\title{
Uso político de programas sociales y nuevos intermediarios institucionales: el Programa Progresa/Oportunidades en el sur de Veracruz*
}

\author{
Felipe Hevia de la Jara
}

\begin{abstract}
La literatura sobre clientelismo político en México confirma que la utilización de programas sociales con fines electorales tiene una larga tradición. Una vía para estudiar las formas de uso político en el Programa Progresa/Oportunidades es comprender la interacción entre los beneficiarios y el Programa. A lo largo del artículo se sostiene que esta interacción se basa en la emergencia de nuevos intermediarios, quienes han suplantado a los tradicionales. Esto es posible debido a que su ubicación les permite intercambiar recursos e información clave entre actores locales y extralocales, generar capital político y mejorar sus posiciones al interior de las estructuras de poder locales.
\end{abstract}

PALABRAS CLAVE: intermediación, antropología política, clientelismo, pobreza-México,Veracruz

\section{Political Use of Social Programs and New Institutional Intermediaries. Progresa/ Oportunidades Programs in Southern Veracruz}

The literature on political clientelism in Mexico confirms that the utilization of social programs with electoral purposes has a long tradition. One way to study the forms of political use in the Progresa/Oportunidades Program is to understand the interaction between the beneficiaries and the Program. Throughout the paper argues that this interaction is based on the emergence of new intermediaries, who have replaced traditional rural intermediaries. This is possible because of their location enabling them to share resources and information among key local and extralocal actors, generate political capital and improve their positions within the local power structures.

KEYWORDS: brokerage, clientelism, patronage system, poverty-Mexico,Veracruz

Felipe HeVIa DE LA JARA: Centro de Investigaciones y Estudios Superiores en Antropología Social-Golfo, Xalapa, México fhevia@ciesas.edu.mx

Desacatos, núm. 34, septiembre-diciembre 2010, pp. 119-132

Recepción: 30 de noviembre de 2007 / Aceptación: 2 de septiembre de 2008

* Este artículo se basa en resultados de mi tesis doctoral. Agradezco los comentarios y correcciones de Samana Vergara Lope, Ernesto Isunza, Jonathan Fox y de los dictaminadores anónimos, así como a FAPESP. Los errores y omisiones son de mi exclusiva responsabilidad. 


\section{INTRODUCCIÓN}

$\mathrm{E}$ $n$ años recientes los procesos electorales en México se han caracterizado, con contadas excepciones, por altos niveles de abstencionismo, campañas electorales "sucias" que incluyen la intervención de los gobernantes (federales, estatales y municipales) y resultados con márgenes estrechos entre ganadores y perdedores (Aziz, 2007; Crespo, 2007). En este contexto, aumentan las posibilidades de que el acceso o la permanencia en los programas sociales se utilicen con fines político-electorales. La literatura sobre clientelismo político en México confirma que la utilización de programas sociales con estos fines tiene una larga y fuerte tradición, y que esta práctica se ha modificado con el paso del tiempo, con una tendencia a la reducción de la coacción y una persistencia de acciones de compra de votos a cambio de acceder a programas sociales (Fox, 1994; Cornelius, 2002; Schedler, 2004; Díaz Cayeros, 2007; Fundar et al., 2006).

Uno de los programas que ha generado mayor investigación al respecto es el Progresa/Oportunidades (PO). lud y Alimentación-Progresa y en 2002 cambió a Oportunidades. Desde 2004 tiene un padrón de más de 5 millones de familias beneficiarias, está presente en todos los municipios del país y en 2007 ejerció un presupuesto de 35 mil millones de pesos (Oportunidades, 2007a). Por su diseño y operación, sin mecanismos de control gubernamental y social, el PO podría cooptarse fácilmente para fines político-electorales o patrimonialistas: al seleccionar a quién benefician y a quién no (focalización), al entregar apoyos en efectivo directamente a las familias (transferencias económicas) y al establecer corresponsabilidades para recibir los apoyos (condicionamiento de los apoyos) se generan importantes espacios de discrecionalidad. En este sentido, para evitar usos indebidos, los arquitectos del Programa diseñaron mecanismos de control, principalmente la transparencia en algunos procesos clave (como la selección de beneficiarios), y una política de información y blindaje electoral (como la publicación de los registros de beneficiarios), al tiempo que establecieron la pauta para eliminar la intermediación entre los beneficiarios y el gobierno (Oportunidades, 2003b; Levy y Rodríguez, 2004).

La literatura que analiza el uso político-electoral en el PO se ha centrado en dos grandes temáticas: la distribución geográfica de los recursos económicos con fines electorales (Rocha, 2001; Takahashi, 2007; De la O, 2003; Díaz Cayeros, 2007); y la percepción de los beneficiarios del Programa Oportunidades sobre las prácticas de compra y coacción del voto (Vilalta, 2007; Palma, 2007; Fundar et al., 2006; Alianza Cívica, 2006). Este artículo se inserta en una tercera línea de aproximación abordada ya por la antropología en México: analizar las interacciones entre los beneficiarios y el Programa (Escobar, 2000; Anaya, 2000; Escobar y González de la Rocha, 2002; González de la Rocha y Escobar, 2002). A lo largo del artículo se sostiene que esta interacción se basa en la emergencia de nuevos intermediarios, creados por el propio Programa, quienes han suplantado a los tradicionales en el uso electoral y particular de algunos espacios de discrecionalidad.

Así, se argumenta que el Programa Oportunidades se utiliza menos con fines clientelares que los demás programas sociales, tanto por su diseño institucional —el PO busca que los beneficiarios se relacionen con él de manera directa y sin intermediarios- como por la falta de capacidades e interés de los propios brokers tradicionales. Sin embargo, debido a limitaciones de gestión, el Programa tuvo que crear sus propios intermediarios institucionales: los enlaces y las vocales del Comité de Promoción Comunitaria (CPC). La posición de estos nuevos intermediarios les permite, entre otras cosas, hacer uso político-electoral del Programa, sin llegar a transformar la práctica necesariamente en una forma de clientelismo autoritario.

Este artículo se basa en información etnográfica recolectada entre 2004 y 2005 en el sur del estado de Veracruz, en especial en el municipio indígena de Pajapan, ubicado en la sierra de Santa Marta, habitado por 14071 personas, con $61 \%$ de hablantes de náhuatl y considerado de muy alta marginación (INEGI, 2003). En 2005 el Programa atendía a 2075 familias de un total de 2487 en el municipio, es decir, a 82.9\%. Para 2006 aumentó el número de familias a $2886-90 \%$ del total de los hogares del municipio- (Oportunidades, 2006b). Es decir, la inmensa mayoría de habitantes del municipio de Pajapan es beneficiaria del PO. 


\section{USO POLÍTICO E INTERMEDIARIOS}

En general, la literatura define el clientelismo político como las acciones de compra y coacción de votos. La compra incluye el ofrecimiento de ciertos servicios o beneficios a cambio del voto, y la coacción implica desde amenazas, condicionamiento de apoyos y servicios, hasta violencia en las casillas electorales y el robo de boletas (Cornelius, 2002:14; Fundar et al., 2006; Alianza Cívica, 2006; FEPADE, 2006; Vilalta, 2007; Schaffer y Schedler, 2007).

Jonathan Fox (1994) define la compra y coacción del voto como prácticas clientelares autoritarias y las contrapone a las prácticas pluralistas -el uso legítimo que se hace de las acciones gubernamentales en una democracia- y a las prácticas semiclientelares — aquellas que en principio podrían ser consideradas legítimas, como las solicitudes de voto, la propaganda electoral y la invitación a votar por un partido o por otro, pero que difieren del pluralismo porque "los actores estatales aún intentan violentar el derecho a la autonomía de las asociaciones" (Fox, 1994: 158)—. Así, el uso político de los programas puede incluir, además de las versiones negativas de coacción y compra, prácticas legítimas de retorno político, en el sentido de premiar electoralmente a los responsables por la implementación de un programa o servicio determinado, pero en medio de estas posibilidades existen amplias zonas grises donde predominan las prácticas semiclientelares. Dentro de la coacción pueden situarse en mayor proporción las acciones clientelares autoritarias directas, en especial las amenazas de suspender el apoyo si los beneficiarios no votan por determinado partido político; aunque, como plantea Vilalta (2007), su definición y análisis están mucho menos desarrollados que el de la compra.

En lo que se refiere a la compra de votos, como plantean Auyero (2001), Dehouve (2006) y Schaffer y Schedler (2007), estas acciones suponen un complejo intercambio entre "compradores" y "vendedores" que sitúa esta práctica más allá de una simple transacción económica. Atributos positivos como la reciprocidad, la confianza y la amistad, y negativos, como el control y la amenaza, se mezclan en una multiplicidad de significados que sin duda hacen más complicadas estas relaciones "clientelares"

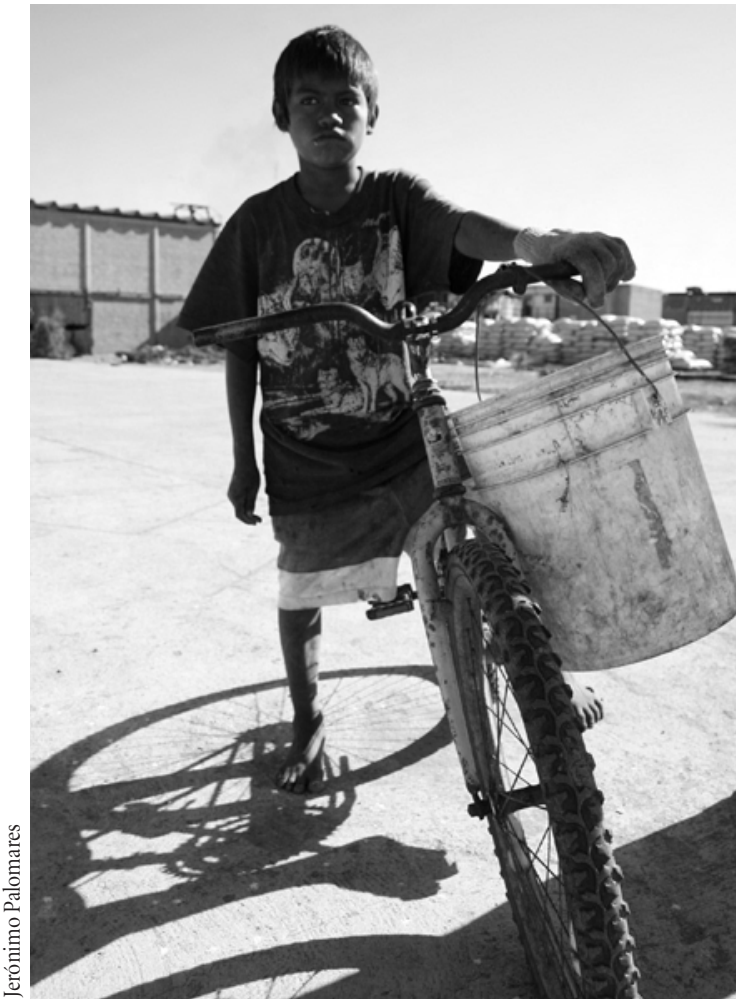

Niño pescador, 2006.

(Auyero, 2001). Desde el punto de vista de compradores y vendedores de votos, surge una serie de características que alejan esta práctica del "mercado". Para los primeros, resulta difícil asegurarse de que la otra parte cumpla su trato. Para los clientes, la compra de votos, dependiendo del contexto, tiene una multiplicidad de significados: puede representar un anticipo de las elecciones, un salario después de las mismas, un regalo o una reparación, una afrenta o una amenaza, un signo de virtud, de vicio o un vínculo de fortaleza (Schaffer y Schedler, 2007: 12-15). De ahí que sea necesario incorporar al análisis la economía del don que implican los procesos electorales, sobre todo a nivel local (Deohuve, 2006). Esto quiere decir que el ofrecimiento de ingresar a un programa social puede ser considerado un presente o un don, que como contra-don precisa que los beneficiarios entreguen sus votos. Esta economía política del voto puede también pensarse tomando como don los votos (como la primera parte de la apuesta 
hacia el futuro) para que el candidato, como contra-don, cumpla sus ofrecimientos (Fundar et al., 2006: 87). También es preciso analizar la racionalidad del voto en estos procesos de compra o solicitud. ¿Hasta qué punto votar sobre un cálculo racional — por ejemplo, si voto por X candidato me ponen luz o me darán trabajo- puede considerarse "compra" de votos? ¿Dónde está el límite entre ofertas electorales legítimas y compra de votos? La respuesta está en los procesos autoritarios, y muchas veces ilegales, por medio de los cuales los "compradores" se aseguran de que los "comprados" cumplan con su parte de la transacción (Shaffer y Schedler, 2007; Fox, 1994).

Dentro de estas complejas tramas que se activan en épocas electorales, la labor de los intermediarios resulta central para poder explicar cómo operan las instancias que permiten el uso clientelar de los programas sociales. La antropología política en México ha desarrollado ampliamente el concepto de intermediario político, desde los estudios de Wolf (1956) sobre los broker hasta los análisis sobre elecciones políticas (Adler-Lomnitz, 2001), pasando por los temas de caciquismo, caudillismo, intermediarios políticos e intermediarios culturales y económicos (Salmerón, 1984; De la Peña, 1986, 2004). De la Peña (1986: 33-38) realiza una síntesis de estos estudios, definiendo tres tipos de intermediación (que pueden ser operados por el mismo sujeto): cultural, política y económica. Los intermediarios se construyen a lo largo del tiempo y son quienes tejen las complejas relaciones de amistad, reciprocidad y cercanía que después pueden activarse para fines "clientelares". Entonces, las preguntas son: ¿quiénes son los intermediarios en el caso del PO?, ¿usan estos intermediarios su posición con fines clientelares?, ¿qué candados institucionales genera el Programa para evitar esto?

\section{ACTORES LOCALESY USO POLÍTICO}

Desde las primeras evaluaciones de impacto del Programa (Adato, Coady y Ruel, 2000; Escobar, 2000; Anaya, 2000), diversas fuentes apuntan a que los intermediarios que usan con fines político-electorales el PO son actores locales. El análisis de las quejas y denuncias por proselitismo político del Sistema de Atención Ciudadana (Opor- tunidades, 2007b), los resultados de estudios de Alianza Cívica (2006), de Fundar et al. (2006), del PNUD (2006) y nuestro propio trabajo en el sur de Veracruz coinciden en afirmar que la coacción del voto es cada vez menos utilizada en el PO, en comparación con otros programas sociales (del presente y del pasado), así como en identificar a las autoridades y funcionarios locales (vocales, enlaces y profesionales de la salud) como los principales actores que usan el Programa con fines clientelares, sobre todo por medio de prácticas semiclientelares.

Como se muestra en la tabla 1, entre 2004 y 2006 se acumularon relativamente pocas denuncias sobre proselitismo, lo que en parte se explica por los pocos efectos que éstas generan, puesto que prácticamente ninguna tuvo una respuesta satisfactoria (Hevia, 2007). La tabla también revela que los actores con más denuncias son vocales del CPC, es decir, beneficiarios; que los funcionarios públicos con más denuncias de proselitismo son los profesionales de la salud y los funcionarios municipales (el enlace y las autoridades municipales). Pero mientras que en el sector salud aumenta exponencialmente el número de denuncias hechas en su contra en 2005, las autoridades municipales tienden a disminuirlas. Por otra parte, los funcionarios federales (presentados como "Oportunidades") reciben pocas quejas por proselitismo, y sorprende la ausencia de denuncias sobre actores sociales tradicionales, como confederaciones campesinas, asociaciones de ejidatarios o de vecinos. Es decir, más de la mitad de las denuncias son contra vocales y enlaces, cargos creados por el propio Programa; y los intermediarios "tradicionales", como organizaciones campesinas o indígenas, no aparecen como interesados en usar el PO para comprar o coaccionar votos. Como a continuación se argumenta, estas conclusiones son dos caras de la misma moneda.

\section{DISEÑO DE OPORTUNIDADES: EL MIEDO A LA INTERMEDIACIÓN}

El uso político-electoral explícito del anterior programa de combate a la pobreza, el Programa Nacional de Solidaridad-Pronasol, así como su débil impacto en la su- 
Tabla 1. Denuncias por proselitismo recibidas en el Sistema de Atención Ciudadana 2004-2006

\begin{tabular}{|c|c|c|c|c|c|}
\hline $\begin{array}{l}\text { Actores } \\
\text { denunciados }\end{array}$ & 2004 & 2005 & 2006 & Totales & $\%$ \\
\hline Vocales & 145 & 83 & 104 & 332 & $33.64 \%$ \\
\hline $\begin{array}{l}\text { Profesionales de la } \\
\text { salud }\end{array}$ & 22 & 140 & 104 & 266 & $26.95 \%$ \\
\hline Enlaces & 77 & 35 & 39 & 151 & $15.30 \%$ \\
\hline $\begin{array}{l}\text { Autoridades } \\
\text { municipales }\end{array}$ & 64 & 15 & 24 & 103 & $10.44 \%$ \\
\hline Oportunidades & 38 & 27 & 21 & 86 & $8.71 \%$ \\
\hline Educación & 5 & 32 & 12 & 49 & $4.96 \%$ \\
\hline Total & 351 & 332 & 304 & 987 & $100.00 \%$ \\
\hline
\end{tabular}

Fuente: Elaboración propia con base en Oportunidades (2007b).

peración de la pobreza, generaron en los creadores de Progresa la intención de diferenciarse de Pronasol, lo cual definió dimensiones centrales de su diseño (centralización, focalización del gasto en zonas rurales, énfasis en el capital humano), pero también las formas de relación entre el gobierno y los beneficiarios (Hevia, 2008). Los principales cambios fueron concebir a la familia, y no a la comunidad, como el foco de intervención, y limitar toda posibilidad de intermediación entre el gobierno federal y las familias beneficiarias. El argumento principal fue que, al transferir el dinero directamente a las familias, el Programa no precisaba de estructuras de intermediación local (Anaya, 2000; Levy y Rodríguez, 2004). En este sentido, se consideraba que, en general, las estructuras locales de intermediación — gubernamentales y sociales — en las zonas rurales eran atrasadas, poco preparadas (muchos presidentes municipales rurales no tenían la educación primaria terminada) y corporativas (y por eso, clientelares y corruptas). Así, se diseñaron diversos mecanismos para eliminar la intermediación local y fomentar la transparencia en la operación. Se eliminó la posibilidad de que un municipio o una organización solicitara "cuotas" para sus agremiados, y las recomendaciones por parte de profesores o médicos sobre qué familias eran realmente pobres o quiénes "no lo necesitaban".

La participación de la comunidad y sus organizaciones sólo tuvo un espacio reducido en el diseño del Programa: una vez seleccionadas las familias beneficiadas, tenía que realizarse una asamblea comunitaria para detectar posibles errores de inclusión (gente que había sido seleccionada pero que "no necesitaba" del Programa) y de exclusión (personas pobres no consideradas), aunque año con año las evaluaciones externas denunciaron su ineficiencia como mecanismo de control (Adato, 2004; Escobar y González de la Rocha, 2005). Al parecer, este diagnóstico no estaba errado. El público objetivo del PO se caracteriza por su desprotección y fragilidad social. Al estar focalizado principalmente en zonas rurales y al ser las mujeres sus interlocutoras centrales, las asimetrías de poder son más evidentes. ¿¿ué posibilidades tiene una mujer indígena que no habla español de denunciar a la autoridad municipal que la obliga a participar en un mitin o la amenaza con retirar el apoyo si no vota por determinado partido?

El diseño de la participación del Programa limita la capacidad de los beneficiarios para resolver este tipo de problemas, porque los obliga a enfrentarse individualmente a la estructura de gobierno, y las instancias de participación institucional a veces resultan ser más parte del problema que de la solución. La situación se agrava cuando consideramos el contexto histórico de las relaciones sociedad-Estado en el México rural, caracterizado por constantes abusos de poder por parte de las autoridades públicas (Bartra, 1975). A lo largo del siglo XX se crearon $\mathrm{y}$ fortalecieron instancias de representación, sobre todo 
en el campo, como las asambleas de ejidatarios y de comuneros, que mantienen niveles relativamente altos de legitimidad. Además, existen federaciones y confederaciones campesinas que en el periodo posrevolucionario fueron centrales para los equilibrios del régimen y que conservan su influencia en el campo de las políticas agrarias (como su participación en programas como la Alianza para el Campo). Diversas organizaciones no gubernamentales, sociales y civiles también están presentes en muchas localidades pobres donde opera el Programa, laas cuales trabajan con las mismas mujeres que reciben Oportunidades.

Sin embargo, la vigilancia o participación en el Programa no parece importante tanto para las organizaciones "tradicionales", las asambleas comunitarias y ejidatarias, como para las organizaciones campesinas. Los actores organizados, con más posibilidades de defender al público de Oportunidades, no aparecen como demandantes de mayores espacios de participación en el Programa. En gran medida, esta situación se explica por las dinámicas de los sistemas políticos locales. Las organizaciones campesinas más tradicionales por lo general no se involucran con el Programa porque a nivel local es considerado "para mujeres", y además entrega pocos montos a cada una de las familias (aunque en conjunto la suma de estas cantidades es considerable). Estos factores disminuyen el interés de las autoridades campesinas y comunitarias en utilizar su tiempo e influencias para defender eventuales abusos de poder, y al parecer estas instancias participan sólo cuando un problema es muy grave o está muy avanzado $^{1}$. Una porción del potencial interés de estas organizaciones en el Programa tiene que ver con la posibilidad de adquirir recursos por medio del cobro de cuotas o comisiones para los gastos de gestión, pero ante los montos relativamente menores que reciben las familias en Oportunidades resultan de mayor interés otros programas que manejan más recursos para menos beneficiarios, como los de apoyo a los campesinos, en los que estas or-

\footnotetext{
${ }^{1}$ Entre 2004 y 2005, de 31 escritos que llegaron a las oficinas de atención ciudadana por abusos de autoridad, sólo en 25\% de los casos habían participado organizaciones o autoridades locales en la denuncia (Hevia,
} 2007). ganizaciones encuentran menos mecanismos de transparencia y control gubernamental que en Oportunidades.

Es decir, las organizaciones campesinas tradicionales consideran que este Programa sólo es una ayuda menor para las familias. Además, el que sea menospreciado por ser un programa "para mujeres" refuerza la poca importancia simbólica que para estas autoridades tienen en general las mujeres, a pesar de que los operadores políticos que intentan manipular el PO han comprendido lo que representan estas beneficiarias: clientelas políticas menos controladas públicamente y, por tanto, un caldo de cultivo para la generación de líderes políticos en este sector de votantes.

El diagnóstico de los diseñadores y operadores sobre la corrupción y el corporativismo autoritario en algunas organizaciones también es coherente con la literatura que afirma que los actores colectivos no representan necesariamente virtudes cívicas, ni sus prácticas favorecen siempre una profundidad democrática (Dagnino, Olvera y Panfichi, 2006; Gurza Lavalle, 2003). Por otro lado, cuando analizamos el "sistema político indígena" de la sierra de Santa Marta también encontramos dificultades ${ }^{2}$. En la literatura especializada en la región (Uribe, 2002; Münch, 1994) suele describirse a la sociedad política indígena (de marcada identidad cívico-religiosa con las cofradías y mayordomías) como diferente de las autoridades municipales mestizas, encargadas de mediar políticamente entre el gobierno y los indígenas. Sin embargo, en nuestra experiencia de campo encontramos una organización política dentro de la comunidad compuesta de tres esferas relativamente autónomas: política, cívico-religiosa y económica.

Dentro de la sociedad política, los principales actores son los partidos políticos que se enfrentan por el poder municipal, que es el mediador entre la comunidad y los ámbitos estatales y federales y tiene la legitimidad para resolver los conflictos al interior de la misma comunidad ${ }^{3}$.

\footnotetext{
${ }^{2}$ Las características del "sistema político indígena" aquí descritas se limitan a la sierra de Santa Marta y no se pretende dar cuenta de la multiplicidad de formas de gobierno indígena. Para una discusión al respecto, véase Aguirre Beltrán, 1991.

${ }^{3}$ Moreno (2005) afirma que la disputa por el poder municipal en el sur de Veracruz se relaciona más con el mercado de trabajo que con la pugna por proyectos políticos diferentes (de "izquierda" o "derecha"). En
} 


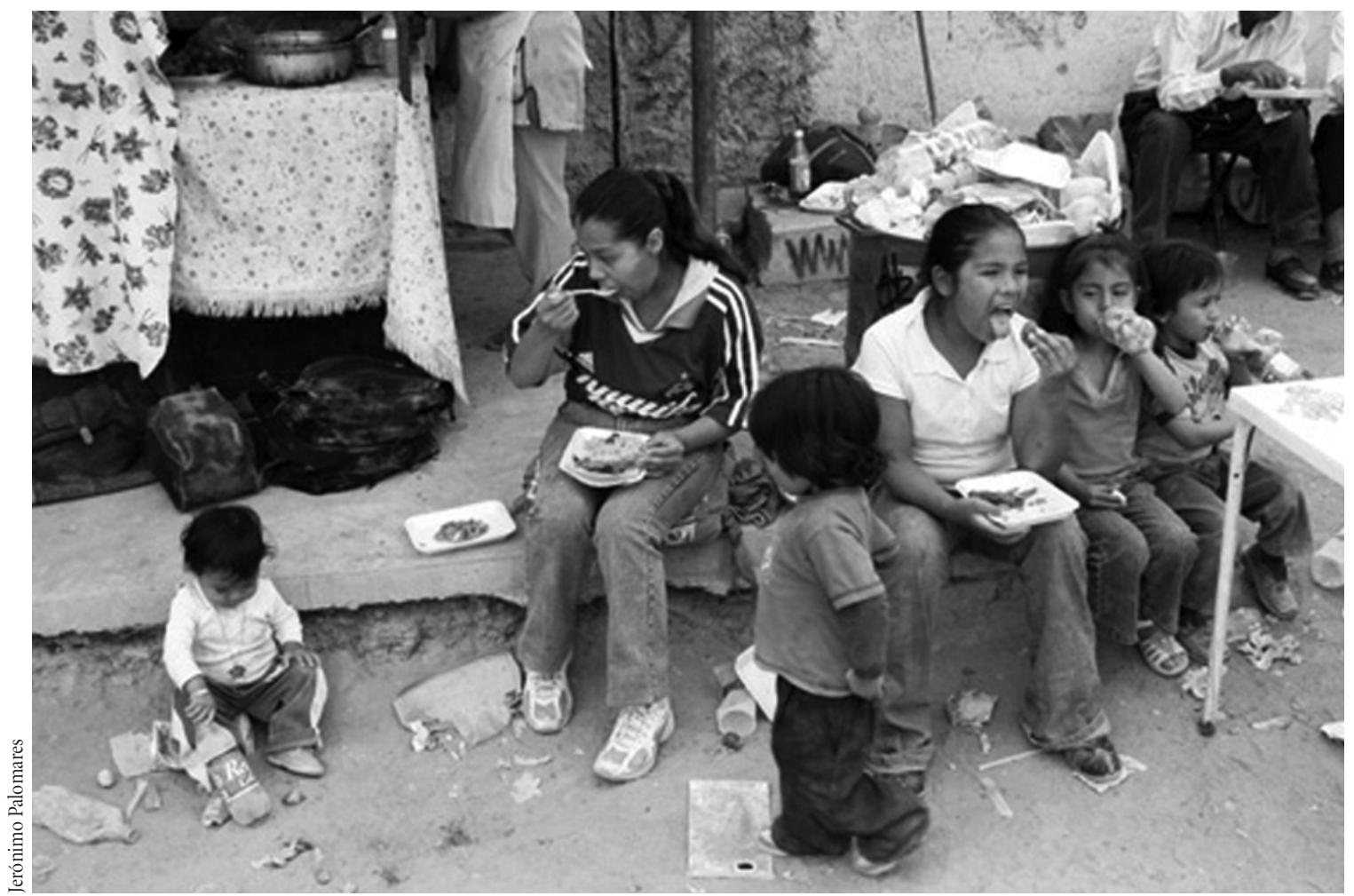

Fuerzas de reserva, 2007.

El poder político se ejerce desde los cargos municipales de representación popular (presidente, síndico y regidor, agentes y subagentes municipales) y, de forma menos clara, por los caciques ganaderos locales, quienes usan su influencia justamente para que sean personas cercanas a ellos quienes accedan a los cargos edilicios. Lo que buscan los grupos y las corrientes es la presidencia municipal, y en esta competencia los cargos cívico-religiosos no parecen tener un papel preponderante. Según mis informantes, ninguno de los últimos cinco presidentes municipales fue o ha sido mayordomo. En la sociedad cívico-religiosa se inclu-

zonas de alta marginación, 11000 pesos quincenales (que corresponden al sueldo del presidente municipal de Pajapan) es considerada una renta muy alta. De hecho, los problemas internos que tuvo la administración municipal en el periodo 2004-2007 fueron principalmente acusaciones de nepotismo, al no poder integrar a todos los interesados en los cargos existentes. ye a las organizaciones religiosas (católicas y cristianas) existentes en la región y a las cofradías. Aquí, los actores son grupos religiosos autónomos entre sí. Las cofradías, de las que surgen los llamados sistemas de cargos, son organizaciones ligadas a la visión tradicionalista de sociedades de fieles que se hacen cargo de celebrar y cuidar de un santo. El responsable es el mayordomo, quien procura la ayuda de una serie de diputados y padrinos para organizar la fiesta. Una de las mayores responsabilidades del mayordomo es dar de comer a todos los invitados (cientos de personas) los días que dure la fiesta, además de pagar la banda de música, los cohetes y las velas. Sin entrar en detalle sobre las interpretaciones del sistema de cofradías, la mayordomía no se busca sólo por prestigio social, ni es exclusiva de los pudientes del pueblo. Tampoco es una suerte de "trampolín" político o algo parecido. El mayordomo encargado entre los años 2004 y 2006 era campesino, no tenía ganado, su esposa era titular del Programa 
Oportunidades y él poseía un solo predio (es decir, 12 ha); tampoco había tenido cargos políticos o públicos, ni había sido comisariado comunal o ejidal. Por último, la sociedad económica incluye a las organizaciones productivas que tienen un peso específico tanto en la esfera política como en la cívico-religiosa, sin llegar a determinarlas. Aquí incluyo a las organizaciones campesinas (comisariado ejidal y comunal), las pescadoras, las ganaderas y las de servicios (transportes, construcción y afines). Los comisariados ejidal y comunal tienen menos vínculos directos con el municipio, aunque mantienen relaciones fluidas con los representantes municipales de los partidos políticos y con otras organizaciones regionales indígenas y campesinas como el Comité de Pueblos Indígenas (CEMPI) y el Movimiento Agrario Indígena Zapatista (MAIZ), entre otros.

Ninguna de las tres esferas establece relaciones de intermediación regulares entre las titulares y el programa, con contadas excepciones. Desde que Oportunidades atiende a la población de Pajapan, sólo encontramos mediación tradicional en dos casos: el cambio de promotoras a titulares en 2002-2003 y la suspensión de algunas faenas obligatorias. Cuando llegó el Programa a Pajapan, alrededor de 1999, la figura comunitaria existente era la promotora, que cobraba entre 10 y 30 pesos por titular el día de pago, además de organizar las faenas obligatorias adicionales a las reglas de operación (barrer calles, arreglar el pueblo para la fiesta municipal, limpiar el centro de salud, chapear y arreglar la carretera entre Pajapan y Tatahuicapan). En el cambio, se incluyó la intermediación de un líder local y la participación de una organización no gubernamental estatal —MAIZ, que por medio de oficios y comunicación directa con la coordinación estatal logró cambiar a las promotoras y al enlace que tenía el cargo en ese momento- - Otra intermediación del sistema político fue la limitación de las faenas obligatorias extra a las reglas de operación (barrido de calles, sobre todo), que fue promesa de campaña del presidente municipal. Estas tareas dejaron de realizarse en la cabecera a partir de 2005 .

Es decir, por razones totalmente atendibles, como querer eliminar el corporativismo autoritario y el clientelismo, el cobro de cuotas, etc., se diseñó un sistema de operación que prescindía de cualquier intermediario. Era el gobierno central el que se relacionaba directamente con cada una de las familias beneficiarias. Sin embargo, para que este diseño tuviera éxito en su operación necesitaba mecanismos directos para comunicarse con sus beneficiarios. Por eso se crearon en los estados, de manera desordenada, varios mecanismos de atención ciudadana para poder escuchar, que fueron coordinados en un sistema único sólo hasta 2003. Así, cada familia tenía la posibilidad (al menos teórica) de poder comunicarse directamente los coordinadores del Programa, por carta o teléfono, sin intermediación. Pero poder hablar de manera directa con sus beneficiarios resultaba más complejo: ¿cómo llegar a cada una de las miles de localidades de las zonas más apartadas de México?, ¿ cómo avisar a las familias qué día se pagaría?, ¿ cómo informarles que no estaban cumpliendo con sus corresponsabilidades y que recibirían menos dinero? Ante la incapacidad del Estado para comunicarse directamente con los beneficiarios, la única solución posible fue crear un sistema de correas de transmisión de la información. Es decir, construir nuevos intermediarios.

En 1999, el Programa Progresa tuvo que incorporar dos figuras que no dependían directamente de la coordinación centralizada: el enlace municipal y la promotora comunitaria. El primero, un funcionario municipal pagado por el ayuntamiento, se encargaba de avisar a las titulares del día de los pagos y de brindar seguridad a las caravanas de pago. Por su parte, la promotora era la "representante" de las beneficiarias y sus principales funciones eran transmitir la información que entregaba el enlace y vigilar que las beneficiarias gastaran adecuadamente los apoyos recibidos (González de la Rocha y Escobar, 2000). Con el cambio de Progresa a Oportunidades en 2002, cuando se comienza a ampliar la cobertura de atención del Programa, los enlaces y las promotoras adquirieron mayores atribuciones, por ser ellos los que intermediaban con los operadores del mismo para actualizar los datos del padrón y realizar otros trámites importantes. Ante el evidente poder que estaban adquiriendo estos actores, el Programa intentó año con año limitar su alcance, hasta desaparecer a los enlaces municipales en las reglas de operación de 2008. 


\section{LOS ENLACES MUNICIPALES}

Los enlaces municipales eran funcionarios designados por el ayuntamiento, que tenían a su cargo facilitar la operación del Programa, y sus funciones, atribuciones y limitaciones se especificaban en las Reglas de Operación, las cuales fueron modificadas constantemente entre 2002 y 2007 hasta su desaparición formal en 2008. Al inicio, la función del enlace era la vinculación entre el Programa y las familias para lo referente a los procesos de incorporación, sin especificar la necesidad de control y monitoreo del perfil de los enlaces (Anaya, 2000; Oportunidades, 2002: 39; 2003a).

Más tarde se estipuló que el enlace fuera designado por el cabildo y no sólo por el presidente municipal. En 2004 y 2005 se incluyeron restricciones a los enlaces municipales, como no ser representantes de alguna organización política o religiosa, la prohibición de adjudicarse la operación del Programa, nombrar o remover vocales o convocar a reuniones no previstas en las Reglas de Operación (Oportunidades, 2004: 15; 2005). En 2006 se prohibió además seleccionar para este cargo a personas relacionadas con indagaciones de delitos electorales (Oportunidades, 2006a: 23). Y en 2008 esta figura dejó de existir. Muchas de sus funciones se traspasaron a los Centros de Atención y Registro (CAR), dependientes de funcionarios contratados por la coordinación estatal.

¿Por qué tuvo que especificarse tanto la norma en relación con los enlaces hasta su posterior desaparición? Principalmente porque los enlaces fueron los intermediarios entre el nivel local y los niveles estatal y federal, transformándose así en uno de los actores mejor posicionados para movilizar diversos tipos de recursos e incrementar su capital —político, simbólico y económico—. Fue tal la cantidad de recursos y capital que lograron acumular y movilizar, que el Programa tuvo que añadir, año con año, normas en su accionar, hasta eliminarlos finalmente de su diseño operativo. Ellos movilizaban recursos entre dos espacios: el local y el extralocal. De lo local hacia lo extralocal, el enlace facilitaba la operación del Programa en todos sus procesos y aligeraba cargas como la entrega de información, la atención a titulares por trámites, etc., que pasaron a ser responsabilidad de las coordinaciones estatales por medio de los CAR (Oportunidades, 2008). De lo extralocal hacia lo local, movilizaban información clave (días de entrega de apoyos y montos, facilidad para acceder a los trámites, etc.), y controlaban la posibilidad misma de acceder al Programa, puesto que la acción del enlace era vital en los procesos de densificación (Escobar y González de la Rocha, 2005). Además, el enlace municipal movilizaba recursos clave hacia sus jefes: el presidente municipal y, por lo regular, el partido o facción política que apoyaba la administración municipal. Del enlace dependía el prestigio que el municipio (el presidente municipal) tuviera ante los operadores del Programa - en el sentido de cooperar con el Programa para acceder a más recursos- y ante la población en general —en la idea de que gracias a las gestiones municipales del presidente y su enlace, más vecinos pudieron acceder al Programa.

¿Cómo distinguir la recompensa política — - legítimade una buena administración del uso político del cargo para el caso de los enlaces? Como las evaluaciones externas muestran, existe mucha variación entre los municipios. Sin embargo, en términos conceptuales, la diferencia radica principalmente en la limitación de la autonomía de los beneficiarios (Fox, 1994), lo que en estos casos se evidencia por medio de la capacidad de "controlar" a las beneficiarias: directamente a las vocales e indirectamente, o por medio de ellas, a las titulares. La idea de "controlar" proviene de la cultura política corporativista mexicana. En el "viejo régimen", los líderes ascendían gracias a la capacidad de movilización de sus corporaciones, con las que tenían relaciones clientelares (muchas veces autoritarias). Esta capacidad de movilización, que se activaba, por ejemplo, en los periodos electorales con los acarreos a los mítines de campaña (Adler-Lomnitz, 2001), muchas veces definía el cargo al que podría aspirar el líder.

En este sentido, los grupos que los enlaces "controlaban" (o pretendían controlar) son dos: las vocales (las otras intermediarias del Programa) y los titulares. Los enlaces tenían la autoridad para citar en nombre del Programa a las vocales, quienes estaban obligados a asistir. El "control" aquí no era meramente simbólico, puesto que estos personajes tenían la capacidad de influir en el cambio de una vocal aduciendo que "no asiste a las reuniones". 
Además, gracias al acceso privilegiado que tenían a la información, y a la solución de problemas operativos que redundaban en potenciales disminuciones del apoyo económico, los enlaces podían desarrollar una relación de "castigo-premio" con las vocales: premiando a las "leales", anticipándoles información, agilizando sus trámites; y castigando a las "desleales", atrasando trámites, retrasando la información, etc. Y siempre, la movilización de estos recursos era posible por su posición de intermediarias. Como plantea Bourdieu:

\begin{abstract}
los que poseen una autoridad delegada pueden obtener toda suerte de beneficios de su posición de intermediarios. Según la lógica del derecho [...], todo acto o proceso administrativo puede ser bloqueado y retardado o facilitado y acelerado (contra una cantidad de dinero). El subalterno tiene a menudo una ventaja en relación con las instancias superiores ( $\mathrm{y}$ con las instancias de control en particular): está próximo al "terreno", y cuando es estable en su puesto, es frecuente que forme parte de la sociedad local (Bourdieu, 2005: 57-58).
\end{abstract}

Este capital se transforma en un activo político sumamente importante. En Pajapan, el enlace municipal era el tercer cargo de confianza más preciado políticamente, sólo por debajo de los de secretario municipal y tesorero. De hecho, en el periodo de campo, el enlace municipal, "Mol"4, fue presidente municipal del Partido Acción Nacional —que por primera vez accedía al municipio — en la época de las elecciones, cargo al que tuvo que renunciar para seguir siendo enlace, pero la población en general lo seguía identificando con ese instituto político. Tenía intenciones de postularse como presidente municipal en la siguiente elección, o por lo menos "dar la lucha".

En el municipio de Coatzacoalcos, el enlace municipal en 2004, "Rodrigo" ${ }^{\text {, }}$ renunció a su puesto para poder hacer campaña electoral por Marcelo Montiel, presidente municipal que se postulaba a diputado local —y que sacó la primera mayoría en las elecciones de 2004 y volvió a ser electo presidente municipal en 2007- Rodrigo es considerado una autoridad importante en el municipio, uno de los operadores de Montiel, y se le denunció varias veces en los medios por usar la estructura del Programa para invitar a reuniones de apoyo a "Marcos", un precandidato del PRI que finalmente perdió contra Iván Hillman, presidente municipal de Coatzacoalcos en el periodo 2004-2006.

En la región ha habido varios enlaces que han incursionado en otros puestos políticos de importancia. El paradigma es el caso de Chinameca, donde el enlace se lanzó con éxito para el cargo de presidente municipal. En Tatahuicapan el enlace también se postuló al mismo puesto en 2004, pero corrió con menos suerte que su antecesor, que a su vez había sido enlace del Programa. En el municipio de Hidalgotitlán, el exenlace mantuvo un puesto importante en el ayuntamiento, como director de los programas sociales.

En 2004, antes de las elecciones en Minatitlán, la entonces enlace municipal estaba en negociaciones al interior del PRI para postularse como regidora o como secretaria del ayuntamiento, y su estrategia de negociación era justamente el potencial de votos que tenía en las comunidades rurales del municipio. Aprovechaba sus visitas a las localidades en su cargo de enlace para que los agentes municipales firmaran cartas de apoyo a su postulación como regidora, y al interior de su partido constantemente hacía mención de la gran cantidad de personas que podía "controlar". En todo caso, no fuimos testigos de ninguna situación directa de compra o coacción de votos, tales como acarreos a titulares, amenazas o presiones de algún tipo.

En resumen, el puesto de enlace municipal era políticamente redituable porque su posición de intermediario le permitía movilizar recursos del espacio local al extralocal y viceversa. Gracias a esta posición, los enlaces pudieron acrecentar su capital político, por un lado, usando el puesto para mostrarse eficientes ante los potenciales votantes y, por otro, "controlando" — muchas veces más en el discurso que en la realidad- a un grupo potencialmente grande de votantes, lo que les permitía negociar en mejores condiciones al interior de su partido o facción y ejercer prácticas clientelares autoritarias o semiclientelares.

\footnotetext{
${ }^{4}$ Nombre ficticio.

${ }^{5}$ Nombre ficticio.
} 


\section{VOCALES DE LOS COMITÉS DE PROMOCIÓN COMUNITARIA}

Las promotoras o vocales se crearon con el fin de mediar entre el Programa y las titulares (Progresa, 1999: 21, 37), y hasta la fecha cumplen funciones similares: informar a las titulares, resolver dudas y preguntas relacionadas con la operación, participar en la vigilancia y ayudar a realizar las corresponsabilidades (oficiales y no oficiales) (Núñez y García, 2000). Al igual que el enlace, las vocales cumplen importantes funciones de intermediación, que conllevan -además de los beneficios y perjuicios descritos - la posibilidad de movilizar y acceder a recursos significativos.

Los más evidentes son los recursos económicos a los que acceden muchas veces por vía de las cooperaciones y las cuotas de las mismas titulares. El tema es más complejo de lo que parece. Por un lado, necesitan una cantidad considerable de tiempo y recursos para atender al grupo de titulares que tienen a su cargo (el Programa no entrega apoyos monetarios específicos para sufragar estos gastos), por lo que piden cooperación o gastan sus propios recursos. Pero, por otro lado, no pueden obligar a las titulares a participar en las cooperaciones (según las vocales muchas titulares son voluntarias). La principal queja contra las vocales tiene que ver con el cobro de cuotas obligatorias. De hecho, el acceso a estos recursos aparece muchas veces como un beneficio no oficial por ser vocal.

Además de los recursos económicos, las vocales tienen acceso a recursos políticos: muchas son "líderes" que tienen otro cargo. Esto ocurrió al principio de manera evidente con las promotoras, y de hecho fue una de las causas del cambio. Las promotoras eran las líderes naturales de las localidades:

No obstante la disposición de la mayor parte de las promotoras comunitarias a participar en Progresa, se han presentado algunos problemas motivados por las propias condiciones de su labor. En algunas ocasiones ellas solicitan cooperación económica de las titulares para sus gastos de traslado. En otros casos, han sido invitadas por diversos tipos de "líderes" para que participen en actividades políticas o sociales en su comunidad (Adato, Coady y Ruel, 2000: 17).
La cooptación política de los cargos, como lo constatan algunas de las limitaciones en la selección de enlaces y vocales en las Reglas de Operación, es un reflejo de la capacidad de movilización que éstos podrían tener, aunque como bien advierten Escobar y González de la Rocha no es una cooptación necesariamente partidista, puesto que más bien responden a la creación de cierto capital político:

En general, los comités estudiados no funcionan como tales, y han mostrado poco liderazgo en otros ámbitos. Su funcionalidad ha dependido de que tengan buenas relaciones con los enlaces, y de que este contacto sea útil para o bien crear cajas solidarias, o bien atraer proyectos productivos [...] Por otra parte, gradualmente crean contactos que son útiles en otros sentidos, de ahí el peso de las expromotoras en varias comunidades. Este liderazgo (que en términos políticos es una forma de brokerage o intermediación) puede necesitar vigilancia, pero se vuelve funcional para la comunidad y para las beneficiarias. El liderazgo puede ser partidista, pero no siempre lo es. Aunque algunas expromotoras y vocales disfrutan las relaciones clientelistas y aprovechan su posición, por ejemplo para "orientar" los procesos de recertificación y densificación, sólo en una minoría de casos es claramente partidista (Escobar y González de la Rocha, 2005: 311).

En el caso de las vocales, existe una prohibición específica de acceder a cargos municipales y locales en elecciones locales. Las titulares tampoco pueden postularse al Comité de Promoción Comunitaria si apoyan activamente a un candidato. Sin embargo, no queda claro si las beneficiarias pueden postularse a cargos de elección popular sin tener por ello que renunciar al Programa. No conocemos datos ni estudios sobre la cantidad de titulares que se han postulado a cargos de elección popular. En nuestro trabajo de campo no conocimos ningún caso de vocales que hayan sido candidatas a algún puesto popular, y en el único al que tuvimos acceso había poca claridad al respecto. En Soconusco, Veracruz, una vocal quería postularse para agente submunicipal, pero las fuerzas políticas locales no estaban de acuerdo, aduciendo que "como era funcionaria pública del Progresa, no podía participar”. El caso llegó al Subconsejo Técnico Estatal de Minatitlán, donde los enlaces comentaron que esta señora "no podía participar en política”. El caso no quedó en actas y final- 
mente se adujo que si la vocal quería postularse, tenía que renunciar al Programa (no al CPC, como marcaban las Reglas de Operación).

Finalmente, la posibilidad de acceso a capital económico y político por la labor de intermediación de la vocal también se debe a la funcionalidad que tiene ésta dentro del sistema, sobre todo en caso de problemas o irregularidades. Muchas titulares se acercan a ellas cuando tienen algún problema o cuando algo no funciona bien:

En cuanto al vínculo de las titulares con este agente comunitario voluntario y la relevancia de su actividad, destaca que $85 \%$ de las mujeres consulta a la promotora cuando tiene dudas sobre el funcionamiento del Programa, proporciones que son considerablemente mayores que aquellas que acuden con el mismo propósito con los médicos de las unidades de salud o con los maestros (Progresa, 1999: 369-370).

\section{CONCLUSIONES}

La manipulación política de los programas sociales, más que la excepción, pareciera ser la regla en la historia reciente de México. Como mostramos a lo largo de este artículo, una vía para estudiar las formas de uso político de los programas sociales es comprender la construcción y funciones de los intermediarios entre el gobierno y sus beneficiarios. Los programas sociales, sin mecanismos de transparencia ni control por parte de la sociedad, han sido históricamente utilizados con fines electorales en México. En este contexto, el PO resultó un programa innovador puesto que estableció mecanismos de transparencia que redundaron en una disminución de la compra y la coacción de votos. Sin embargo, no logró desaparecer la intermediación. Si bien se limitó la acción de los intermediarios "tradicionales", por restricciones de gestión y por diseño, el Programa tuvo que crear sus propios intermediarios.

Estos nuevos intermediarios, como vimos en el sur de Veracruz, muchas veces no lograron abstraerse de la dinámica histórica de uso político de los programas sociales y del interés constante de los actores y operadores políticos por intentar usarlos. A diferencia de otros programas sociales, Progresa/Oportunidades desarrolló una serie de mecanismos para acotar el poder de estos intermediarios, como el endurecimiento y la constante modificación de sus Reglas de Operación, con el fin de restringir el acceso de operadores políticos al cargo de enlaces; la generación de campañas de información para explicar a las titulares sus derechos y eliminar así una parte importante de las prácticas de amenazas y coacción; y la creación de un sistema de atención ciudadana, que en la práctica tiene capacidad limitada para resolver denuncias relacionadas con proselitismo (Hevia, 2007).

Sin embargo, dadas las limitaciones de las capacidades gubernamentales para comunicarse directamente con las titulares, y los beneficios que la posición de intermediario representa para vocales y enlaces, no fue posible romper esta dinámica histórica. El control de recursos mejoró sustantivamente las posiciones de enlaces y vocales al interior de las comunidades y localidades, muchas veces a costa de la reedición, limitada pero constante, de prácticas clientelares —relacionadas sobre todo con el supuesto "control" de grupos voluminosos de votantes-. Por último, para los beneficiarios del Programa, la presencia de nuevos intermediarios significó dejar de depender de intermediarios tradicionales para acceder a apoyos centrales para la reproducción familiar, pero seguir potencialmente expuestos a prácticas clientelares autoritarias, no ya sólo del cacique, sino además del médico, del enlace o la vocal.

\section{Bibliografía}

Adato, Michael, 2004, "Programas de transferencias monetarias condicionadas focalizadas. Beneficios y costos sociales", en J. Boltvinik y A. Damián (comp.), La pobreza en México y el mundo. Realidades y desafíos, Gobierno del Estado de Tamaulipas, Siglo XXI, México, pp. 348-363.

Adato, Michael, David Coady y Marie Ruel, 2000, "Evaluación de operaciones de Progresa desde la perspectiva de los beneficiarios, las promotoras, directores de escuela y personal de salud", en Progresa, Evaluación de resultados del Programa de Educación, Salud y Alimentación. Aspectos operativos del Programa, 2000, Progresa, México, pp. 3-337.

Adler-Lomnitz, Larissa, 2001, Redes sociales, cultura y poder: ensayos de antropología latinoamericana, Miguel Ángel Porrúa, Flacso, México. 
Aguirre Beltrán, Gonzalo, 1991, Formas de gobierno indígena, Obra antropológica, vol. IV, Universidad Veracruzana, Instituto Nacional Indigenista, Fondo de Cultura Económica, Gobierno del Estado de Veracruz, México.

Alianza Cívica, 2006, Segundo Informe del Monitoreo de Programas Sociales. Junio 2006, Alianza Cívica, México.

Anaya, Juan Manuel, 2000, "La gestión municipal en el Programa de Educación, Salud y Alimentación (Progresa)”, en A. Escobar y M. González de la Rocha (comps.), Más oportunidades para las familias pobres. Evaluación de resultados del Programa de Educación, Salud y Alimentación. Aspectos comunitarios. 2000, Progresa, México, pp. 39-55.

Auyero, Javier, 2001, La política de los pobres. Las prácticas clientelistas del peronismo, Cuadernos Argentinos, Manantial, Buenos Aires.

Aziz, Alberto, 2007, "El retorno del conflicto. Elecciones y polarización política en México", Desacatos, núm. 24, pp. 13-54.

Bartra, Roger, 1975, Caciquismo y poder político en el México Rural, Siglo XXI, México.

Bourdieu, Pierre, 2005, "De la casa del rey a la razón de Estado. Un modelo de la génesis del campo burocrático", en L. Wacquant (coord.), El misterio del ministerio. Pierre Bourdieu y la política democrática, Gedisa, Barcelona, pp. 43-69.

Cornelius, Wayne, 2002, "La eficacia de la compra y coacción del voto en las elecciones mexicanas de 2000", Perfiles Latinoamericanos, vol. 20, pp.11-31.

Crespo, José Antonio, 2007, "Empate, conflicto e incertidumbre", Desacatos, núm. 24, pp. 181-194.

Dagnino, Evelina, Alberto Olvera y Aldo Panfichi, 2006, "Introducción, para otra lectura de la disputa por la construcción democrática en América Latina”, en E. Dagnino, A. Olvera y A. Panfichi (comps.), La disputa por la construcción democrática en América Latina, Fondo de Cultura Económica, Centro de Investigaciones y Estudios Superiores en Antropología Social, Universidad Veracruzana, México.

De la O, Ana, 2003, "Evaluación política del Programa Oportunidades”, ponencia, Seminario Diez años del Cambio en la Política Social: Retos y Perspectivas del Programa Oportunidades, 11 diapositivas, Centro de Investigación para el Desarrollo, México.

De la Peña, Guillermo, 1986, "Poder local, poder regional: perspectivas socioantropológicas”, en Jorge Padua y Alain Valenzuela (comp.), Poder local, poder regional, El Colegio de México, Centro de Estudios Mexicanos y Centroamericanos, México, pp. 27-56.

- 2004, Los nuevos intermediarios étnicos, el movimiento indígena y la sociedad civil: dos estudios de caso en el occidente mexicano, Cuadernos de la Sociedad Civil 9, Centro de Investigaciones y Estudios Superiores en Antropología Social, Universidad Veracruzana, México.
Dehouve, Danielle, 2006, Economía política del don, conferencia magistral, Centro de Investigaciones y Estudios Superiores en Antropología Social, México.

Díaz Cayeros, Alberto, 2007, Los programas sociales y su efecto electoral en México: un análisis cuasi-experimental, Serie ENAPP núm.1, Programa de Naciones Unidas para el Desarrollo, México.

Escobar, Agustín, 2000, "Progresa y el bienestar de las familias. Los hallazgos”, en A. Escobar y M. González de la Rocha (comps.), Más oportunidades para las familias pobres. Evaluación de resultados del Programa de Educación, Salud y Alimentación. Aspectos comunitarios. 2000, Progresa, México, pp. 3-31.

Escobar, Agustín y Mercedes González de la Rocha, 2002, Evaluación cualitativa del Programa de Desarrollo Humano Oportunidades. Seguimiento de impacto 2001-2002. Comunidades de 2500 a 50000 habitantes. Evaluación de resultados de impacto del Programa de Desarrollo Humano Oportunidades, Centro de Investigaciones y Estudios Superiores en Antropología Social, México.

__ 2005, Evaluación cualitativa del Programa Oportunidades en zonas urbanas, 2003, en Bernardo Hernández y Mauricio Hernández (ed.), Evaluación externa de impacto del Programa Oportunidades 2003, Instituto Nacional de Salud Pública, Centro de Investigaciones y Estudios Superiores en Antropología Social, México.

Fiscalía Especializada para la Atención de Delitos Electorales (FEPADE), 2006, "Blindaje electoral. Informe final”, FEPADE Informa, núm. 12.

Fox, Jonathan, 1994, "The Difficult Transition from Clientelism to Citizenship: Lessons from Mexico", World Politics, vol. 46, núm. 2, pp.151-184.

Fundar et al., 2006, Monitoreo de programas sociales en contextos electorales, México, en línea: <http://www.fundar.org.mx/ programassociales/2Encuesta.pdf $>$, consultado el 14 de septiembre de 2006.

González de la Rocha, Mercedes y Agustín Escobar, 2002, Resultados de la evaluación cualitativa basal del Programa de Educación, Salud y Alimentación (Progresa) semiurbano, septiembre-diciembre de 2001, Centro de Investigaciones y Estudios Superiores en Antropología Social-Occidente, México.

Gurza Lavalle, Adrián, 2003, "Sem Pena nem Glória. O Debate Sobre a Sociedade Civil nos anos 1990”, Novos Estudos, Centro Brasileiro de Análise e Planejamento, núm. 66, pp. 91109.

Hevia de la Jara, Felipe, 2007, "La contraloría social en el Programa Oportunidades desde una óptica de interfaz socioestatal", en Luciano Tatagiba et al., Contraloría y participación social en la gestión pública, Centro Latinoamericano de Administración para el Desarrollo, Caracas. 
_ 2008, "Individual or Collective Action. Citizen Participation and Public Oversight in Mexico's Oportunidades Programme”, ids Bulletin, vol. 38, núm. 6, pp. 64-72.

Instituto Nacional de Estadística y Geografía (INEGI), 2003, Anuario Estadístico de Veracruz, CD-ROM, Instituto Nacional de Estadística y Geografía, México.

Levy, Santiago y Evelyne Rodríguez, 2004, "El Programa de Educación, Salud y Alimentación, Progresa-Programa de Desarrollo Humano Oportunidades", en S. Levy (comp.), Ensayos sobre desarrollo económico y social de México, Fondo de Cultura Económica, México, pp.181-379.

Moreno, Saúl, 2005, “Corporativismo y resistencia civil en el sureste petrolero mexicano”, ponencia, 1er. Congreso Nacional de Antropología desde la Frontera Sur. Perspectivas de Estudio en el Siglo XXI, Chetumal.

Münch, Guido, 1994, Etnología del istmo veracruzano, Instituto de Investigaciones Antropológicas, Universidad Nacional Autónoma de México, México.

Núñez, Ana y Georgina García, 2000, "Las características de las promotoras comunitarias Progresa y el desarrollo de su actividad", en Progresa, Evaluación de resultados del Programa de Educación, Salud y Alimentación. Impacto en el trabajo y las relaciones intrafamiliares, Programa de Educación, Salud y Alimentación, México, pp. 301-329.

Oportunidades, 2002, Reglas de Operación para el Ejercicio Fiscal 2002, Coordinación Nacional de Oportunidades, México.

__, 2003a, Reglas de Operación para el Ejercicio Fiscal 2003, Coordinación Nacional de Oportunidades, México.

— , 2003b, Programa Institucional Oportunidades, 2002-2006, Coordinación Nacional Oportunidades, México.

—_, 2004, Reglas de Operación para el Ejercicio Fiscal 2004, Coordinación Nacional de Oportunidades, México.

—_, 2005, Reglas de Operación para el Ejercicio Fiscal 2005, Coordinación Nacional de Oportunidades, México.

—_, 2006a, Reglas de Operación para el Ejercicio Fiscal 2006, Coordinación Nacional de Oportunidades, México.

_ 2006 b, Padrón de familias beneficiarias, cuarto bimestre 2006, Municipio Pajapan, en línea: <www.oportunidades. gob.mx>, consultado el 3 de octubre de 2006.

—_, 2007a, Reglas de Operación para el Ejercicio Fiscal 2007, Coordinación Nacional de Oportunidades, México.

_, $2007 \mathrm{~b}$, Sistema de Registro, Control y Seguimiento de la Demanda Ciudadana, Base de datos sistema MS Excel, Dirección General de Atención y Operación, Coordinación Nacional de Oportunidades, México.
, 2008, Reglas de Operación para el Ejercicio Fiscal 2008, Coordinación Nacional de Oportunidades, México.

Palma, Esperanza, 2007, Problemas para la construcción de ciudadanía: un análisis de los beneficiarios del Programa Oportunidades, Serie ENAPP, núm. 3, Programa de Naciones Unidas para el Desarrollo, México.

Programa de Naciones Unidas para el Desarrollo, 2006, Diagnóstico sobre la vulnerabilidad político-electoral de los programas sociales, pnud, México.

Programa de Educación, Salud y Alimentación (Progresa), 1999, Más oportunidades para las familias pobres. Evaluación de resultados del Programa de Educación, Salud y Alimentación. Primeros Avances, 1999, Programa de Educación, Salud y Alimentación, México.

Rocha Menocal, Alina, 2001, "Do Old Habits Die Hard? A Statistical Exploration of the Politicisaction of Progresa, Mexico's Latest Federal Poverty-Alleviation Programme, under the Zedillo Administration", Journal of Latin American Studies, vol. 33, pp. 513-538.

Salmerón, Fernando, 1984, "Caciques: una revisión teórica sobre el control político local", Revista Mexicana de Ciencias Politicas y Sociales, vol. 30, núms. 117-118, pp. 107-141.

Schaffer, Frederic y Andreas Schedler, 2007, “¿Qué significa la compra de votos?”, ponencia, Seminario Internacional Candados y Derechos, Programa de Naciones Unidas para el Desarrollo, México.

Schedler, Andreas, 2004, “'El voto es nuestro'. Cómo los ciudadanos mexicanos perciben el clientelismo electoral", Revista Mexicana de Sociología, vol. 66, núm. 1, pp. 57-97.

Takahashi, Yuriko, 2007, “The Political Economy of Targeted Poverty Alleviation: Distributive Politics, Electoral Cycles, and Progresa-Oportunidades in Mexico", ponencia, Latin American Studies Association, International Congress-2007, 5-8 septiembre, Montreal.

Uribe, Manuel, 2002, Identidad étnica y mayordomías en zonas de alta concentración industrial. El caso de los nahuas, popolucas y zapotecas del istmo veracruzano en el siglo XX, tesis de doctorado, Universidad Veracruzana, Xalapa.

Vilalta, Carlos, 2007, Compra y coacción del voto en México: variaciones estatales y diferencias de opinión entre beneficiarios y no beneficiarios de programas sociales, Serie ENAPP, núm. 4, Programa de Naciones Unidas para el Desarrollo, México.

Wolf, Eric, 1956, "Aspects for Groups Relations in a Complex Society: Mexico", American Anthropologist, vol. 58, núm. 6, pp. 1065-1978. 